\title{
Latent Heat Storage with Phase Change Materials (PCMs)
}

\author{
H.L. Zhang ${ }^{1, *}$, J. Baeyens ${ }^{2}$, J. Degrève ${ }^{1}$ and F. Pitié ${ }^{3}$ \\ ${ }^{1}$ Department of Chemical Engineering, Chemical and Biochemical Process Technology and Control Section, \\ Katholieke Universiteit Leuven, Heverlee, Belgium \\ ${ }^{2}$ School of Engineering, University of Warwick, Coventry, UK \\ ${ }^{3}$ Whittaker Engineering Ltd., Stonehaven, Scotland
}

\begin{abstract}
Latent heat thermal energy storage with phase change materials (PCMs) is attractive since providing a high energy density storage due to the phase change by solidification/melting at constant temperature. Relative to sensible heat energy storage systems, latent heat storage with PCMs requires a smaller weight and volume of material for a given amount of captured/stored energy, and has the capacity to store heat of fusion at a constant or nearly constant temperature, thus maintaining a high and constant temperature difference between the heat exchanging surface and the PCMs.

The present review paper will summarize the required properties of PCMs, with their respective advantages and disadvantages; the current state of development and manufacturing; the development of PCM applications, including their incorporation into heat exchangers, insertion of a metal matrix into the PCM, the use of PCM dispersed with high conductivity particles. PCM uses will be illustrated through some case-studies.
\end{abstract}

Keywords: Heat storage, Latent heat, Sensible heat, Phase change materials, Encapsulation.

\section{INTRODUCTION}

\section{Energy and the Required $\mathrm{CO}_{2}$ Reduction}

Energy supply has progressively become a vital issue. The Kyoto Protocol crystallized the concerns of the public regarding the emission of greenhouse gases and the need to reduce the use of fossil fuels [1]. The global economic crisis since 2008 added additional challenges [2]. This global concern about energy and $\mathrm{CO}_{2}$ emissions, lead worldwide governments to enact new policies and financial incentives in support of renewable energies, enhancing their implementation and development, whilst simultaneously creating valuable new business opportunities for companies involved in this energy sector [3,4]. One of the hot topics in the energy strategy is the capture and storage of thermal energy and waste heat recovery. Both advanced energy utilisation schemes call for the development and new usage of existing and/or new materials. These new materials, and their potential use, are the subject of the present paper.

Based upon current statistics and predictions of energy consumption, the U.S. Energy Information Administration in 2011 predicated an increase of the total world energy use from $14810^{9} \mathrm{MWh}$ in 2008 to $18110^{9} \mathrm{MWh}$ in 2020, and to $22510^{9} \mathrm{MWh}$ in 2035 [2]. Since liquid fuels remain an important source of

*Address correspondence to this author at the Department of Chemical Engineering, Chemical and Biochemical Process Technology and Control Section, Katholieke Universiteit Leuven, Willem De Croylaan 46, Bus 2423, 3001 Heverlee, Belgium; Tel: +32 163226 95; Fax: +32 163229 91;

E-mail: huili.zhang@cit.kuleuven.be energy, albeit with depleting reserves, their prices are expected to remain and/or exceed $130 \$ /$ barrel. Because of the use of fossil fuels, current global $\mathrm{CO}_{2}$ emissions are at $30.610^{9}$ tpa of $\mathrm{CO}_{2}$ (against $28.210^{9}$ tpa in 2005). Without effective measures, it is however expected that world energy-related emissions of $\mathrm{CO}_{2}$ will further increase to $33.510^{9}$ tpa in 2015 and 43.2 $10^{9}$ tpa in 2035.

There is still a considerable scope for improving energy efficiency. In a short or medium term, waste heat recovery and high temperature thermal energy storage (HTTES) are crucial concepts to implement such solutions, and even power plants can use HTTES to improve the energy balance of their operations, since HTTES increases the flexibility and availability of heat and electricity in traditional or sustainable power plants.

The imposed reduction in $\mathrm{CO}_{2}$ emissions will require a combination of detailed strategies and tactics, including (i) a mix of energy generation technologies; (ii) a reduction in energy usage through the use of incentives, technologies, taxes and quotas; (iii) maximising $\mathrm{CO}_{2}$ absorption, as carbon sequestration by both natural means and by technical developments; and (iv) the development of highly-efficient energy capture, recovery and storage methods $[3,4]$.

\section{Major Opportunities}

Waste heat sources can be of high grade and low grade according to the viability of recovery within the processes.

(C) 2013 Lifescience Global 
The re-use "of low grade heat" is not widespread since it is a technical and economic challenge to obtain useful exergy and energy from low grade heat. The temperature range of low grade heat sources is typically between ambient temperature and $250^{\circ} \mathrm{C}$. The market potential for surplus/waste heat from industrial processes in the UK is between 10 TWh to 40 TWh [5, 6]. A large amount of low grade heat is available in the process industry as e.g. water from cooling towers with gas temperatures between $35^{\circ} \mathrm{C}$ and $55^{\circ} \mathrm{C}$, and stack exhausts with a broader temperature range, between $30^{\circ} \mathrm{C}$ and $\sim 180^{\circ} \mathrm{C}$.

The barriers associated with low grade heat utilisation [7] include (i) the need to match the sources with potential end-users around the process plant; (ii) the difficulty in harnessing the potential of the waste water streams available at lower temperatures (between 35 and $55^{\circ} \mathrm{C}$ ), whilst achieving economical benefits; (iii) the economic and geographic limits towards distances of pumping recovered heat (steam, hot water); and (iv) the heat losses, the total cost for pipeline installation, and pumping cost.

In "high grade heat" applications, electricity generation and solar energy are the key topics. We need energy - electrical or thermal - but in most cases where and when it is not available. Energy storage technologies are a strategic and necessary component for the efficient utilization of renewable energy sources and energy conservation. These energy sources can be used more efficiently through the addition of short and long term energy storage, that enable an extensive and more efficient use of the fluctuating energy sources by matching the energy supply with demand.

Low cost, fossil fuel-based electricity has always served as a considerable cost competitor for electrical power generation and traditional power plants store their energy resource on site in the form of a stock of e.g. coal, oil, nuclear fuel or even water behind a dam. The Alternating Current $(A C)$ electricity grid requires that supply and demand is always matched on a second by second basis, and electricity network and transmission system operators have arrangements in place to ensure that this requirement is always met. The traditional electricity market is therefore largely based on fuels sold and traded as commodities, and used to generate electricity to instantaneously match supply with demand. A future electricity system predominantly or solely supplied by renewable energy sources will therefore find it difficult to meet the fundamental stability requirement of $A C$ networks to constantly match supply and demand [8].

The present paper reviews the current developments of heat storage in PCMs, with their respective advantages and disadvantages; the development of PCM applications, including their incorporation into heat exchangers, insertion of a metal matrix into the PCM, the use of PCM dispersed with high conductivity particles. PCM uses will be illustrated through some case-studies.

\section{GENERALITIES ABOUT HIGH TEMPERATURE HEAT STORAGE}

HTTES is the storing of thermal energy at high temperature which can be drawn upon at a later time to perform some operations [9]. Despite the stake pointed out by HTTES, very few industrial sectors apply energy storage. In the development of such applications, there are three priorities being (i) the development and use of low-cost materials with a long life and thermo- chemical stability; (ii) the design of efficient thermal exchanger and storage architectures; (iii) the development of strategies which can be easily adapted to industrial settings.

There are three main types of storage media as a function of the underlying phenomena being the sensible and/or latent heat storage, and the application of reversible chemical reactions: they store heat in materials which change of temperature, change of phase or change through chemical reaction, respectively.

For high temperature purposes, sensible heat has already been extensively studied and experimented at a large scale [10]. Regarding chemical heat storage, despite its attractive application for long term energy storage, it is still at an early stage of laboratory research, as illustrated further in the paper. Latent heat allows more compact, efficient and therefore economical systems to operate.

Phase change materials (PCM) mainly use the liquid-solid transition to store latent heat. They are generally studied for thermal storage use [4]. PCMs are made from very different types of material, both of organic (e.g. parafins, waxes, fatty acids) and inorganic nature (e.g. melting salts, eutectic metal mixes, hydrated salts), as initially classified by Zalba et al. [11].

For high temperature purposes, phase-changing solids (including salts) have been commonly chosen as 
the cheapest and most efficient PCMs to store heat energy. Due to their low thermal conductivity, they have however slow charging and discharging rates. In order to enhance their thermal properties, different techniques have been studied such as the use of porous graphite media, or finned heat exchangers. Results from Acem et al. [12] and Pincemin et al. [13] proved that a micro-encapsulation in a graphite matrix is a possible and efficient solution. Recent research by the authors has demonstrated that the use of imbedded metal foam is very efficient.

Although the micro-encapsulation of PCM had been previously used to produce slurries [14], or for building applications [15], it has not yet been used for high temperature purposes. The main challenge of this approach would be to develop a compatible and efficient encapsulation of the PCM by a high conductivity material, suitable for high temperature purposes. Techniques such as Plasma Vapour Deposition and Electrolysis have been investigated by the authors, but proven unsuccessful due to the porosity of the encapsulation, letting the molten salt escape from its matrix because of its volume expansion. More research is needed.

\section{HIGH TEMPERATURE THERMAL ENERGY STORAGE}

\section{Objectives}

Developing highly effective energy saving solutions is paramount in the current energy demand context. The objective of this section is to review the available information on the high temperature thermal energy storage (HTTES), in order to define the priority research objectives to complete the fundamentals needed for its widespread application. The review part specifically focuses upon (i) the underlying storage mechanisms and its potential, (ii) the essential materials and properties that delineate temperature ranges of application, and (iii) the illustration of particular solutions to high temperature thermal energy storage. After a brief description of thermal energy storage (TES), the advantages of storing both sensible and latent heat are discussed.

Energy Storage (ES) is the storage of some kind of energy that can be drawn upon at a later time and usefully re-applied in a given operation. It has the potential of increasing the effective use of energy equipment and is normally applied to balance the possible mismatch between the supply of, and demand for energy [9]. The imperativeness of ES results from the need of having the energy production decoupled from its supply and distribution, and to support the intermittent nature of producing alternative energy [16]. An energy storage process is based on three fundamental steps: charging (loading), storing and discharging (releasing). As a result, ES applications facilitate energy management, help bridging power supply/needs and power quality, and increase the system reliability. Energy forms include mainly mechanical, chemical, electrical or thermal energy, and all of them can be stored using an appropriate method, system or technology as summarized below.

\section{Energy Storage Systems: Generalities}

Energy storage systems are classified by the form of energy stored, as shown in Figure 1. Only thermal energy storage is considered in the present paper.

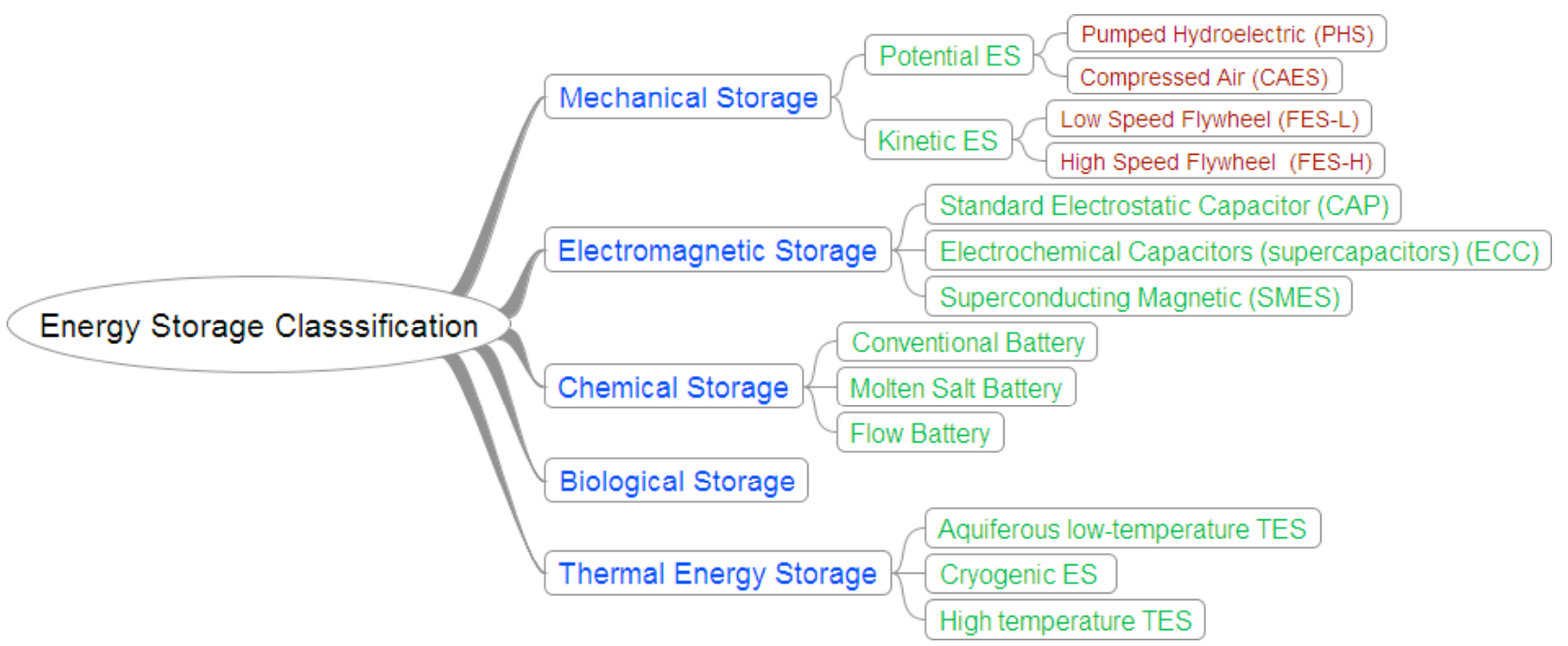

Figure 1: Classification of energy storage systems [9]. 
The Thermal Energy Storage (TES) systems cover a large range of temperatures and applications.

\section{Thermal Energy Storage}

With Thermal Energy Storage (TES), heat is transferred to storage media during the charging period, and released at a later stage during the discharging step, to be usefully applied e.g. in generating high pressure steam for the power block (Rankine cycle) in solar plants, or as heat carrier in high temperature industrial processes, such as metallurgical transformations [17]. In terms of storage media, a variety of choices exists depending on the storage media system selected, the temperature range and the specific application.

Low temperature thermal energy storage (LTTES) operates in a temperature range below $200^{\circ} \mathrm{C}$ and has been extensively investigated and developed. LTTES applications can be found in building heating and cooling [15], in solar cooking, in solar water boilers and air-heating systems, and in solar greenhouses [18-20].

High temperature thermal energy storage (HTTES) plays a vital role in renewable energy technologies and waste heat recovery. There is a wide range of industrial applications where waste heat can be recovered, as in the manufacturing of construction materials (e.g. clay brick or cement kilns) mining and in the metallurgical industry in general [17]. Today, most HTTES usages are however focused upon applications of solar thermal energy, and are the subject of constant innovative research and designs, as summarized by some of the co-authors of the present paper in Fernandes et al. [4]. The current section presents a guideline for a specific TES solution.

\section{TES Requirements}

In order to make HTTES a plausible and attractive alternative for improving the efficiency of industrial processes and solar engineering, some requirements must be fulfilled. HTTESs firstly need to stably operated in a high range of temperatures, which in the present context is specified from $200^{\circ} \mathrm{C}$ to an as high a temperature limit as possible. Secondly, the material used as storage media must be inexpensive, available in sufficient quantities and compatible with a costeffective system design. Several additional facts need to be considered when deciding on the storage media for a HTTES, and the most important requirements are presented by Zalba et al. [11]:
- Energy capacity: high energy density in the storage material;

- Efficiency: good transfer between the heat transfer fluid (HTF) and the storage medium;

- Mechanical and chemical stability of the storage material during the multiple charging/discharging cycles;

- Safety: compatibility between HTF, heat exchanger and/or storage medium;

- Lifespan: complete reversibility in multiple charging/discharging cycles;

- $\quad$ Low heat losses;

- $\quad$ Ease of control;

- $\quad$ Adequate maximum load;

- $\quad$ Appropriate nominal temperature.

Meeting all these requirements needs innovative engineering approaches shaped by the development and research into the fields of storage media. The combination of high efficiency and high energy density requirements can lead to the development of a storage media that makes the design of cost-efficient HTTES viable, and it is a challenge that demands novel ideas and pioneering efforts.

\section{TES Media}

An assertive material selection involves choosing an adequate form of thermal storage, mostly being the thermal storage as sensible heat and/or as latent heat when phase transformations are accounted for. The energy released or absorbed by a material as its temperature is reduced or increased, is called sensible heat, and the specific heat $\left(c_{p}\right)$ is the relevant characteristic. The energy required to convert a solid into a liquid, or a liquid into a gas (material phase change) is called latent heat with e.g. heats of fusion and condensation recognised for their high value. The capacity of energy storage is significantly higher when latent heat storage complements the sensible heat storage. The third and less developed category of heat storage, the thermo-chemical heat storage, intends to apply the reversible endothermic/exothermic reactions but is at a very early stage of research and development. 


\section{Sensible Heat Storage}

Sensible heat storage materials undergo no phase change within the temperature range required for the storage application. Table 1 summarizes the main characteristics of the most common solid and liquid sensible HTTS materials [4].

Within the indicated solids, concrete and cast ceramics have been extensively studied due to their low costs, good thermal conductivities and moderate specific heats. In terms of liquids, molten salts are widely used in power tower systems, being liquid at ambient pressure, providing an efficient and low cost medium, having their operating temperatures compatible with current high-pressure and hightemperature turbines (temperature range over $120^{\circ} \mathrm{C}$ to $600^{\circ} \mathrm{C}$ ), whilst being non-flammable and non-toxic. These molten salts are already used in the chemical and metallurgical industries as heat-transport fluid. From Table 1, it is clear that the main candidates for liquid sensible heat storage are either a solar salt, i.e. a binary salt consisting of $60 \%$ of $\mathrm{NaNO}_{3}$ and $40 \%$ of $\mathrm{KNO}_{3}$, that melts at $221^{\circ} \mathrm{C}$ and is kept liquid at $288^{\circ} \mathrm{C}$ in an insulated storage tank; or HitecXL, a ternary salt consisting of $48 \% \mathrm{Ca}\left(\mathrm{NO}_{3}\right)_{2}, 7 \% \mathrm{NaNO}_{3}$, and $45 \%$ of $\mathrm{KNO}_{3}$ operating beyond its melting point of $130^{\circ} \mathrm{C}$.

Common mineral particles, such as silicon carbide, crystobalite silica, and dolomite also exhibit high values of $\mathrm{C}_{\mathrm{p}}$.
Sensible heat materials have been widely studied and are currently applied in solar thermal plant applications, despite important disadvantages that can affect the storage system design and stability. The low solidification point may be a problem for solar power plants because of the required heat trace during nonfunctioning periods. Furthermore, the sensible fraction of thermal energy is seldom fully recovered due to the required temperature difference as heat transfer driving force. Another important disadvantage consists in the low energy storage density of sensible heat materials, which are required in large volumes or quantities in order to deliver the amount of energy storage necessary for HTTES applications. The above mentioned problems can imply significant increments in the costs of sensible heat storage systems.

\section{Thermo-Chemical Heat Storage}

The main advantage of the thermo-chemical heat storage systems consists in the potentially high energy density of the occurring reversible chemical reactions, which can be even higher than what is usually encountered for the other thermal storage processes. Materials that have been mostly investigated for chemical storage are the $\mathrm{SnO}_{x} / \mathrm{Sn}$ and ammonia system. In the former case, the metal oxide/metal reactions are possible and technically feasible; occurring at a temperature of $980 \mathrm{~K}$, and $\mathrm{SnO}_{2}$ (solid) is reduced with $\mathrm{CH}_{4}$ while it floats on top of liquid $\mathrm{Sn}$. For the latter case, ammonia is dissociated producing

Table 1: Main Characteristics of Sensible Heat Storage Solid and Liquid Materials

\begin{tabular}{|c|c|c|c|c|c|}
\hline \multirow{2}{*}{ Storage Medium } & \multicolumn{2}{|c|}{ Temperature } & \multirow{2}{*}{$\begin{array}{l}\text { Average Density } \\
\left(\mathrm{kg} / \mathrm{m}^{3}\right)\end{array}$} & \multirow{2}{*}{$\begin{array}{c}\text { Average Heat } \\
\text { Conductivity }(\mathrm{W} / \mathrm{m} \mathrm{K})\end{array}$} & \multirow{2}{*}{$\begin{array}{c}\text { Average Heat } \\
\text { Capacity (kJ/kg K) }\end{array}$} \\
\hline & Cold $\left({ }^{\circ} \mathrm{C}\right)$ & Hot $\left({ }^{\circ} \mathrm{C}\right)$ & & & \\
\hline Sand-rock-mineral oil & 200 & 300 & 1700 & 1 & 1.3 \\
\hline Reinforced Concrete & 200 & 400 & 2200 & 1.5 & 0.85 \\
\hline $\mathrm{NaCl}$ (solid) & 200 & 500 & 2160 & 7 & 0.85 \\
\hline Cast iron & 200 & 400 & 7200 & 37 & 0.56 \\
\hline Silica fire bricks & 200 & 700 & 1820 & 1.5 & 1 \\
\hline Magnesia fire bricks & 200 & 1200 & 3000 & 1 & 1.15 \\
\hline HITEC Solar Salt & 120 & 133 & 1990 & 0.60 & - \\
\hline Mineral oil & 200 & 300 & 770 & 0.12 & 2.6 \\
\hline Synthetic oil & 250 & 350 & 900 & 0.11 & 2.3 \\
\hline Silicon oil & 300 & 400 & 900 & 0.1 & 2.1 \\
\hline Nitrite salts & 250 & 450 & 1825 & 0.57 & 1.5 \\
\hline Nitrate salts & 265 & 565 & 1870 & 0.52 & 1.6 \\
\hline Carbonate salts & 450 & 850 & 2100 & 2 & 1.8 \\
\hline Liquid sodium & 270 & 53 & 850 & 71 & 1.3 \\
\hline Silicon Carbide & 200 & 1400 & 3210 & 3.6 & 1.06 \\
\hline $\mathrm{SiO}_{2}$ (Cristobalite) & 200 & 1200 & 2350 & 0.92 & 1.13 \\
\hline
\end{tabular}


hydrogen and nitrogen. The exothermic reaction heat from ammonia synthesis is suitable for electric power generation in conventional Rankine Cycles. Despite its high energy density, thermo-chemical heat storage is considered to be an expensive alternative and is, at the present, at early stages of development.

\section{Latent Heat Storage}

Latent heat storage is based on the heat absorption or heat release that occurs when a storage material undergoes a phase change. Latent storage systems based on phase change materials (PCMs) with solidliquid transition are considered to be very efficient in comparison to liquid-vapour and solid-solid transitions [18]. Liquid-gas transition requires a large volume recipient for the PCM and the solid-solid transition presents a low value of latent heat. Therefore these last two alternatives are not considered appropriated choices. A large number of materials are known to melt with a high heat of fusion within different ranges of temperature. No material yet studied has all the optimum characteristics required for a PCM, and the selection of a PCM for a given application requires careful consideration of the properties of the various substances and/or mixtures [21]. The main characteristics required for PCMs are indicated in Table $2[4,18]$.

As an example, commercial or potential substances used as PCM are shown in Tables $\mathbf{3}$ and $\mathbf{4}$.

All data were previously presented by Fernandes et al. [4], with only specific additional references added to the Table.

\section{Table 2: Main Desirable Characteristics of PCMs}

\begin{tabular}{|l|l|}
\hline Thermal properties & $\begin{array}{l}\text { Phase change temperature suitable within the desired operating range. } \\
\text { High latent heat per unit mass. } \\
\text { High specific heat. } \\
\text { High thermal conductivity for both solid and liquid phases. }\end{array}$ \\
\hline Physical properties & $\begin{array}{l}\text { High energy density. } \\
\text { Low density variation during phase change. } \\
\text { No super cooling during freezing. }\end{array}$ \\
\hline Chemical properties & $\begin{array}{l}\text { Chemical stability. } \\
\text { No chemical decomposition. } \\
\text { Compatibility with container materials construction (e.g. vessels and piping). } \\
\text { Non-toxic, non-inflammable and non-explosive. }\end{array}$ \\
\hline Economic Factors & $\begin{array}{l}\text { Available in large quantities. } \\
\text { Inexpensive }\end{array}$ \\
\hline
\end{tabular}

Table 3: Organic Compounds for Potential Use as PCM

\begin{tabular}{|c|c|c|}
\hline Organic Compounds & Melting Point $\left.{ }^{\circ} \mathbf{C}\right)$ & Heat of Fusion (kJ/kg) \\
\hline \hline Ammediol & 112 & 213 \\
\hline Paraffin RT110 & 112 & 169 \\
\hline Inorganic E117 & 117 & 45.3 \\
\hline Neopentyl glycol & 125 & 44.3 \\
\hline Neopentylglycol diacrylate & 126 & 275 \\
\hline Isomalt & 147 & 247 \\
\hline Adipic acid & 152 & 275 \\
\hline Dimethylol propionic acid & 153 & 306 \\
\hline Organic A164 & 164 & 27.6 \\
\hline Tromethamine & 172 & 44.6 \\
\hline Trimethylolethan & 198 & 36.9 \\
\hline Pentaerythritol & 260 & \\
\hline
\end{tabular}


Table 4: Inorganic Substances/Compounds for Potential Use as PCM

\begin{tabular}{|c|c|c|c|c|c|}
\hline Inorganic Compounds & $\begin{array}{l}\text { Melting } \\
\text { Point }\left({ }^{\circ} \mathrm{C}\right)\end{array}$ & $\begin{array}{l}\text { Heat of } \\
\text { Fusion } \\
(\mathbf{k J} / \mathbf{k g})\end{array}$ & $\begin{array}{l}\text { Density } \\
\left(\mathrm{kg} / \mathrm{m}^{3}\right)\end{array}$ & $\begin{array}{l}\text { Specific Heat at the } \\
\text { melting point } \\
(\mathrm{kJ} / \mathrm{kg}-\mathrm{K})\end{array}$ & $\begin{array}{c}\text { Thermal } \\
\text { Conductivity } \\
(\mathrm{W} / \mathrm{m}-\mathrm{K})\end{array}$ \\
\hline $\mathrm{Mg}\left(\mathrm{NO}_{3}\right)_{2} \cdot 2 \mathrm{H}_{2} \mathrm{O}$ & 130 & 275 & NA & NA & NA \\
\hline $\begin{array}{c}\text { Hitec XL: } 48 \% \mathrm{Ca}\left(\mathrm{NO}_{3}\right)_{2-} \\
45 \% \mathrm{KNO}_{3}-7 \% \mathrm{NaNO}_{3}\end{array}$ & 140 & NA & 1992 & 1.44 & 0.519 \\
\hline Hitec : $\mathrm{KNO}_{3}-\mathrm{NaNO}_{2}-\mathrm{NaNO}_{3}$ & 142 & 84 & 1990 & 1.34 & 0.6 \\
\hline $\mathrm{LiNO}_{3}-\mathrm{NaNO}_{3}$ & 195 & NA & NA & NA & NA \\
\hline $\mathrm{KNO}_{3} / \mathrm{NaNO}_{3}$ eutetic & 223 & 105 & NA & NA & NA \\
\hline $\mathrm{NaNO}_{3}$ & $307 / 308$ & 74 & $2260 / 2257$ & NA & 0.5 \\
\hline $\begin{array}{c}65.2 \% \mathrm{NaOH}-20 \% \mathrm{NaCl}- \\
14.8 \% \mathrm{Na}_{2} \mathrm{CO}_{3}[21]\end{array}$ & 318 & 290 & 2000 & 1.85 & 1.0 \\
\hline $\mathrm{KNO}_{3}$ & $333 / 336$ & $266 / 116$ & 2110 & NA & 0.5 \\
\hline $\begin{array}{c}22.9 \% \mathrm{KCl}-60.6 \% \mathrm{MnCl}_{2}- \\
16.5 \% \mathrm{NaCl}[21]\end{array}$ & 350 & 215 & 2250 & 0.96 & 0.95 \\
\hline $\mathrm{KOH}$ & 380 & 149.7 & 2044 & NA & 0.5 \\
\hline $\mathrm{MgCl}_{2} / \mathrm{KCl} / \mathrm{NaCl}$ & 380 & 400 & 1800 & 0.96 & NA \\
\hline $\mathrm{Na}_{2} \mathrm{CO}_{3}-\mathrm{BaCO}_{3} / \mathrm{MgO}$ & $500-850$ & NA & 2600 & NA & 5 \\
\hline $\mathrm{Li}_{2} \mathrm{CO}_{3}$ & 618 & NA & 2091 & 2.07 & NA \\
\hline $\mathrm{Sb}_{2} \mathrm{O}_{3}[22]$ & 652 & 387 & 5670 & 0.43 & NA \\
\hline $\mathrm{MgCl}_{2}$ & 714 & 542 & 2140 & NA & NA \\
\hline 80.5\%LiF-19.5\%CaF ${ }_{2}$ eutetic & 767 & 790 & $2100 / 2670$ & $1.97 / 1.84$ & $1.7 / 5.9$ \\
\hline LiF & 850 & $1800 \mathrm{MJ} / \mathrm{m}^{3}$ & NA & NA & NA \\
\hline $\mathrm{Na}_{2} \mathrm{CO}_{3}$ & 854 & 275.7 & 2533 & NA & 2 \\
\hline $\mathrm{K}_{2} \mathrm{CO}_{3}$ & 897 & 235.8 & 2290 & NA & 2 \\
\hline
\end{tabular}

Current experimented uses of PCMs for thermal storage involve low to moderate temperatures (10$100^{\circ} \mathrm{C}$ ) and include solar water-heating systems, solar air-heating systems, solar cookers, solar greenhouses (for curing and drying processes), building acclimatization as in a PCM Trombe wall, PCM wallboards [15], under-floor heating systems and ceiling boards $[18,19]$.

Though PCMs usage in HTTES has been experimented for solar plant applications, it has not yet been commercially used $[9,23]$.

The development of HTTES using PCMs is of increasing interest since they are moderately expensive, have high energy density, can in the future be available in large quantities, and are able to store and release thermal energy at a constant temperature. However, most of PCMs have a low thermal conductivity, leading to low charging and discharging rates and sometimes non suitable field of temperature in the material. Therefore, using PCMs for energy storage in high temperature range applications requires considering new aspects of material selection and development. In addition to adapting PCM melting points to a high temperature range, their characteristics need to be improved in order to increase the efficiency of the charging and discharging processes.

Although PCMs are expected to have a potential advantage towards energy storage in comparison with sole sensible heat storage, Figure 2 below illustrates the temperature range where the efficiency of sensible heat storage can exceed the value of e.g. $\mathrm{Sb}_{2} \mathrm{O}_{3}-\mathrm{PCM}$ : the total heat stored is lower than the sensible heat stored in $\mathrm{SiC}$ and/or $\mathrm{SiO}_{2}$. Molten salts $\mathrm{KNO}_{3}-\mathrm{NaNO}_{3}$ and $\mathrm{NaOH}-\mathrm{NaCl}$, on the contrary, offer a significant advantage

\section{AVAILABLE OPTIONS FOR PCM DEVELOPMENT}

To improve the efficiency of the charging and discharging processes of PCMs, the most relevant parameter to be studied is their thermal conductivity. In 


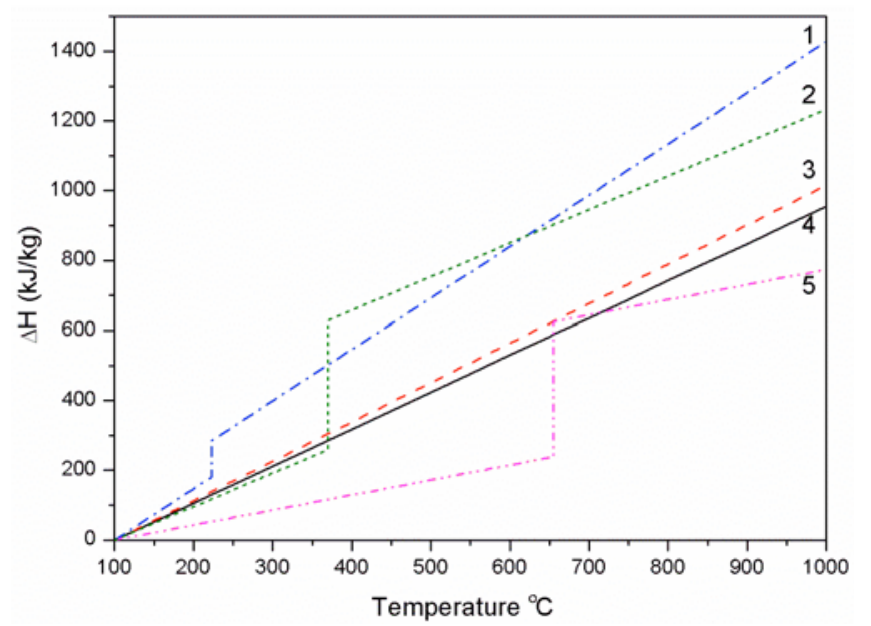

Figure 2: Total heat stored vs. temperature for sensible and latent heat storage materials.

1: $\mathrm{KNO}_{3}-\mathrm{NaNO}_{3}, 2: \mathrm{NaOH}-\mathrm{NaCl}, 3: \mathrm{SiO}_{2}, 4: \mathrm{SiC}, 5: \mathrm{Sb}_{2} \mathrm{O}_{3}$

order to increase the thermal conductivity of PCMs, several heat transfer enhancement techniques have been studied [4, 24-29], such as the use of metal carrier structures made of steel or stainless steel; a dispersion of high conductivity material i.e. copper, silver or aluminium particles, within the PCM; the impregnation of high conductivity porous materials, either as a metal foam (copper, steel or aluminium), or as porous material like graphite; the use of high conductivity, low density materials such as carbon fibres and paraffin composites; and the microencapsulation of PCMs using graphite, polymers, nickel film coating of PCM copper spheres. The general review of these techniques, illustrated in Figure 3, was undertaken by Agyenim et al. [14], and the encapsulation of PCM in shells was determined as being one of the most promising and suitable approaches at the present stage of the investigations.

The reasons behind this selection are the result of the detailed assessment, which summarizes as follows:

- $\quad$ Incorporating metal structures into the PCM has been addressed as one of the thermal

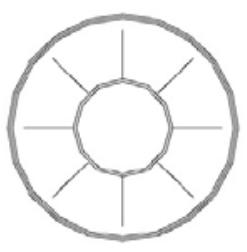

(i) Longitudinal or axial fins

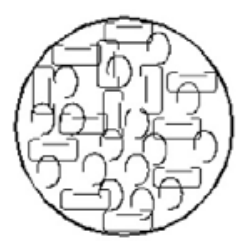

(v) Metal Ri ngs

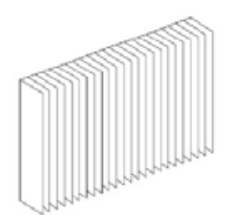

(x) Finned Re ctangular Container

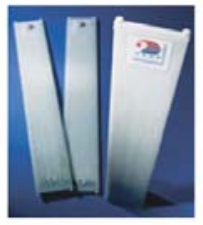

(xv) Polypropylene flat panel

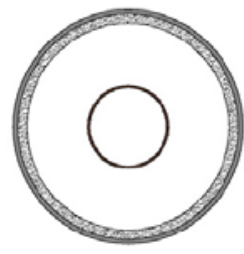

(ii) Circular fins

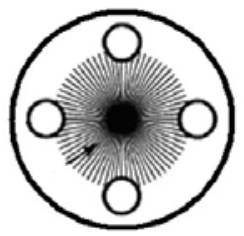

(vi) Multitubes and carbon brushes

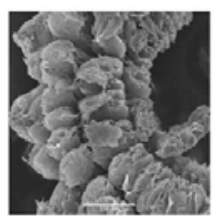

(xi) Graphite flakes

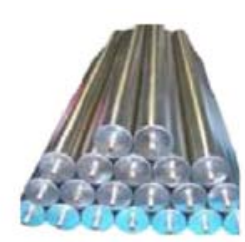

(xvi) Module beam

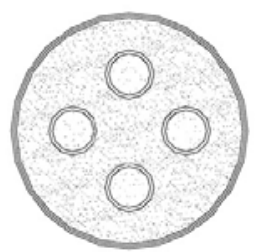

(iii) Multitubes or shell and tube

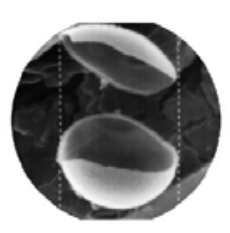

(vii) Encapsulation

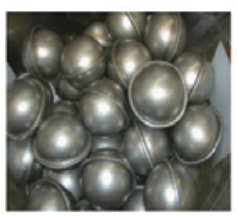

(xii) Steel metal ball capsules

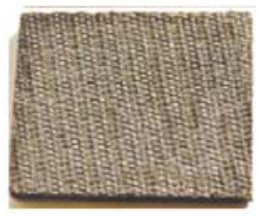

(xvii) PCMGraphite

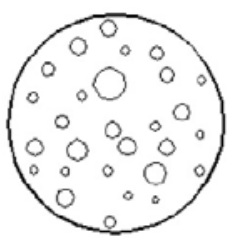

(iv) Bubble agitation

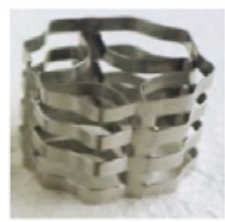

(ix) Metal Matrix

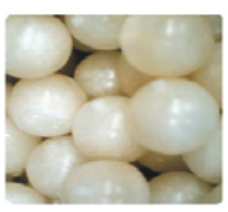

(xiv) Polyolefine spherical balls

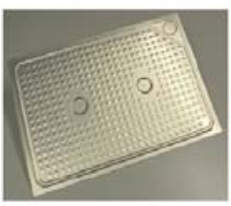

(xviii) Compact flat panel

Figure 3: Heat transfer enhancement methods employed in phase change material research [14]. 
conductivity enhancement techniques by some researchers, who investigated metal structures made of steel or stainless steel in different geometries, such as cylindrical and spherical geometries, and in different arrangements.

- $\quad$ Dispersion of high conductivity particles into the $\underline{\mathrm{PCM}}$ is a relatively simple technique to enhance the thermal conductivity of PCM. Studies involving dispersion of metal particles like copper, silver and aluminium have indicated that there is a limitation in terms of PCM/particle combination that could be applied, and further research is necessary. High conductivity particles should also be compatible with all PCMs. Due to the relatively high density; the metal particles/metal structures may settle at the bottom of the TES container and add considerable weight to the system. According to Fukai et al. [26], not all metal particles are compatible with all PCMs. For example, paraffin and aluminium are compatible, while copper and nickel are not compatible. Similarly, aluminium and copper are not compatible with some salt hydrates. Hence, there has been a search for low-density high conductivity additives which should be compatible with all PCMs, such as carbon fibres [27].

- In view of the above mentioned constraints, integration of high conductivity porous materials in PCMs constitutes an attractive alternative for improving the heat transfer processes in PCMs. The use of a porous matrix has gained increasing attention because of its light weight and high specific surface area for heat transfer
[26]. Porous structures can even be matrices made of aluminium, copper, etc., or naturally available porous materials such as graphite. Since the porous material is impregnated in the PCM, the problem of particle segregation at the bottom of the TES container is reduced.

- $\quad$ The thermal performance of micro-encapsulated PCMs is expected to exceed conventional PCMs since small PCM particles provide larger heat transfer area per unit volume and will provide a higher heat transfer rate. Although studied on a theroretical basis for different combinations of PCMs and coating shells [29-31], the industrial production of such encapsulated PCMs still needs a lot of experimental work, only at its incipient stage at present.

\section{POTENTIAL APPLICATIONS FOR THERMAL ENERGY STORAGE USING CERAMIC ENCAPSULATED PCM}

The layout of the present section is illustrated in Figure 4. Each of the parallel topics is subsequently dealt with.

To illustrate the practical use of the results reported in previous sections, design approaches for thermal energy storage installations are further elaborated. This will be demonstrated by describing potential applications of HTTES or High Temperature Heat Transfer in three typical case studies:

- The encapsulated PCM is mixed within a high temperature $(\mathrm{HT})$ concrete for passive heat energy storage.

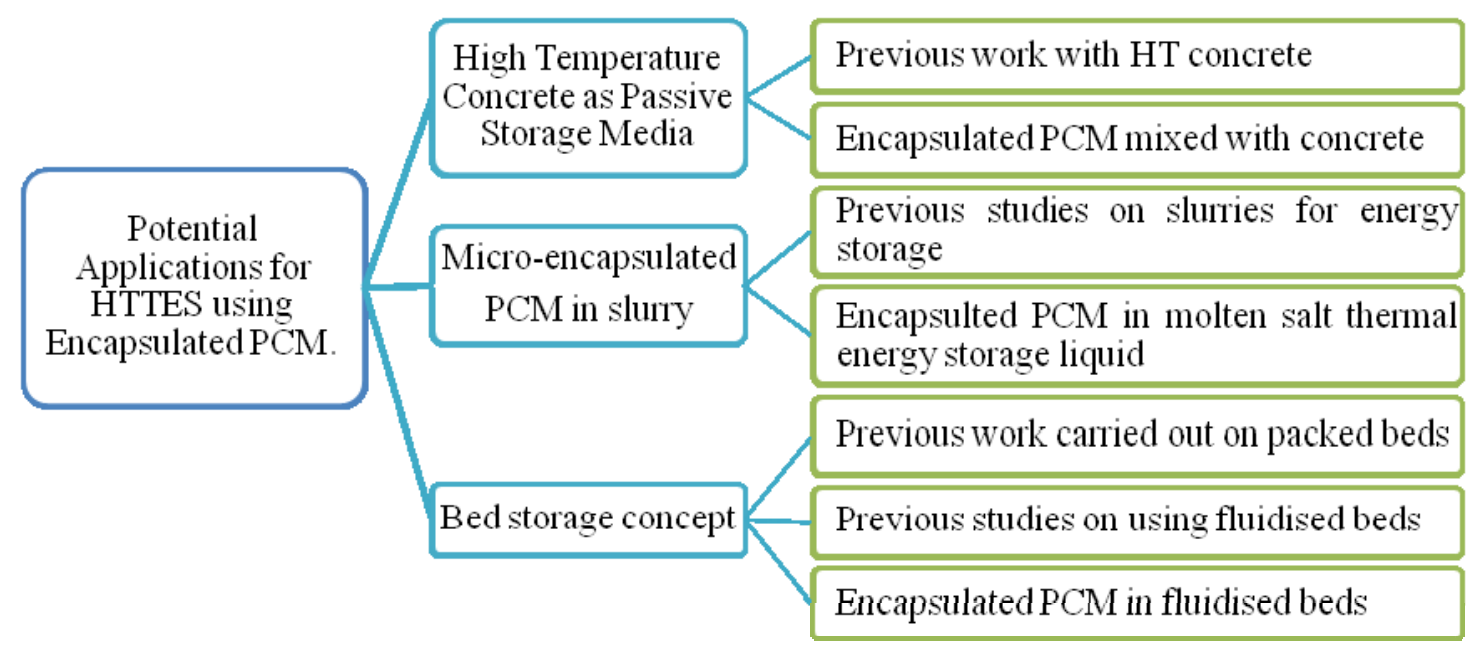

Figure 4: Potential Applications for TES using E-PCMs. 
- $\quad$ The encapsulated PCM is mixed to a liquid heat transfer fluid (HTF).

- $\quad$ The encapsulated PCM is used in a solid-gas conveying system as heat carrier.

In these case studies, the coated PCM interacts with a different heat carrier being: solid, liquid, gas.

\section{High Temperature Concrete as Passive Storage Media}

At the Plataforma Solar de Almeria (PSA) in Southern Spain, Ciemat and the German Aerospace Centre (DLR) tested and proved that both castable ceramics and high temperature concrete are suitable as solid media sensible heat storage systems [10]. The system used the standard HTF in the solar field, which transferred its heat through a system comprising an array of pipes embedded in the solid storage media.

DLR examined the performance, durability and cost of using these solid thermal energy storage (TES) media in parabolic trough power plants. The thermal energy was provided by a parabolic trough loop with a maximum thermal power of $480 \mathrm{~kW}$. The storage temperatures reached were within a range of 340 $390^{\circ} \mathrm{C}$ [10]. In order to raise this technology to precommercial status for use in solar power plants, a 2009 follow-up project was designed by Laing et al. [23]. A three component thermal storage system, combining sensible and latent heat storage was tested for application in DSG power plants [23]. Investigations and experiments supported the hypothesis that hightemperature concrete could serve as sensible heat storage up to $500^{\circ} \mathrm{C}$. Within the limitations of the solid concrete structure, the incorporation of phase-change materials will undoubtedly be beneficial since capable of absorbing a high quantity of energy (sensible and latent heat), while keeping the temperature of the matrix close to the melting point of the phase change.

This use of encapsulated PCM mixed with concrete was further demonstrated for applications at ambient temperatures [15, 19, 32], achieving high energy savings in cooling power. Although, no further studies have yet explored the application of the HT concrete with a proportion of encapsulated PCM, it is evident that the combination of both materials would take advantage of their properties to conserve thermal energy, and thus may lead to a new mixed material worthy of further development. It is however possible that the costs of research and development would mean higher costs at the onset, whilst economies of scale would obviously lead to a reduction in the price in the long term, needed to implement practical and efficient applications [10].

\section{Micro-Encapsulated PCM in Slurry}

A micro-encapsulated PCM slurry is a suspension where the PCM is dispersed at $15-20$ wt\% of the weight without significantly altering the physical properties of the liquid (density, viscosity) [29]: PCM is microencapsulated using a polymeric capsule and dispersed in water. The experimental analysis using a slurry with a $10 w t \%$ concentration of paraffin was conducted by Delgado et al. [28] to investigate the effectiveness of its properties as a thermal storage material and as a heat transfer fluid. The results obtained demonstrated an increase of approximately $25 \%$ in the convective heat transfer coefficient when compared to water. The increase in the efficiency in heat transfer of the liquid is the result of improving the overall heat capacity of the material through applying the latent heat properties of the PCM.

Similarities of shape between the polymeric capsule and the ceramic encapsulated PCMs tend to indicate that the latter could be used to improve the heat transfer coefficient for high temperature slurry applications, as described below.

Nano-particle Enhanced lonic Liquids (NEILs) are a class of low-melting organic compounds with discrete charges that cause a significant decrease in their vapour pressure. At atmospheric pressure, this property prevents volatilization of an ionic liquid (IL), which would recommend its use as a thermal fluid and for energy storage materials [33,34]. The feasibility of using ionic liquids as liquid thermal storage media and heat transfer fluids in a solar thermal power plant has been the subject of additional investigations [34]. According to Bridges et al. [33], nano-particle enhanced ILs have been shown to increase the heat capacity of the IL without adverse secondary effects on the ILs' thermal stability. The IL physical properties were shown to be only affected in cases of high nanoparticle loading [30]. Those similarities between high and low temperature slurries' properties tend to indicate that a high temperature equivalent of an encapsulated PCM slurry is possible.

\section{Encapsulated PCM in Molten Salt Thermal Energy Storage Liquid}

New concentrated solar plants have been under development for some time $[3,35]$. These new designs 
involve a heat storage unit as part of the production process. Using a unique molten salt for both of these applications reduces the cost and improves the global performance of the system.

Such a system could benefit from a heat transfer fluid which incorporates encapsulated particles of PCM. The heat transfer capacities would be improved by the high conductivity and the high energy density of the PCM. In comparison with a conventional thermal fluid, e.g. Santotherm 350, the specific heat will be increasingly by a fraction of $\approx 3$ whilst the energy density will increase by about 5 .

The main issues for developing salt-PCM modifications would be the loss of fluidity of the high temperature slurry. Further studies have to prove if the addition of particles increases the thermal properties of the HTF without affecting the viscosity and associated pumping power needed. Existing CSP would then see their global efficiency improved by the higher energy density of the HTF.

\section{Fluidized Bed Storage Concept}

High heat transfer coefficients can be achieved between a fluidized bed and a heat exchanging surface, containing a PCM [31]: heat will be captured by a particulate gas-solid flowing suspension, whereafter the hot particles will transfer heat to a PCM filled into the tubes of a tube-bundle located in the heat recovery section of the loop. Further research by the authors focuses upon this application, and will be reported in a few months.

Additionally, the development of granular phase change materials, has been undergoing tests since January 2013: the E-PCM particles will be directly used in a circulating fluidized bed heat collector. As in HT concrete, the latent heat would increase the amount of energy stored. The life cycle of the system and aging of the particles require a careful study. If the shells of the PCM were to break or leak, the result would be leakage of the molten salt from the shell and consequent damage to the fluidised bed, by corrosion, defluidization and possible sintering of the bed material if low melting eutectics can be formed.

\section{CONCLUSIONS}

Latent heat thermal energy storage with phase change materials (PCMs) is attractive since providing a high energy density storage due to the phase change by solidification/melting at constant temperature, thus allowing to use a smaller weight and volume of material for a given amount of captured/stored energy. Since phase changes occur at a given constant temperature, the use of PCMs maintains a high and constant temperature difference between the heat exchanging surface and the PCMs.

The present paper reviewed the required properties of PCMs and the current state of development and applications, including their incorporation into heat exchangers. The low thermal conductivity of the PCMs requires enhanced thermal behaviour through inserting a metal matrix or dispersing high conductivity particles within the PCM. Further research and analysis of applications of encapsulated particles will be required in order to precise the field of future successful development in HTTES.

\section{REFERENCES}

[1] Asif M, Muneer T. Energy supply, its demand and security issues for developed and emerging economies. Renew Sust Energ Rev 2007; 11: 1388-13.

http://dx.doi.org/10.1016/j.rser.2005.12.004

[2] IEA, OECD. World energy outlook 2011. IEA, International Energy Agency: OECD, Paris 2011.

[3] Zhang HL, Baeyens J, Degrève J, Cacères G. Concentrated solar power plants: Review and design methodology. Renew Sust Energ Rev 2013; 22: 466-81. http://dx.doi.org/10.1016/j.rser.2013.01.032

[4] Fernandes D, Pitié F, Caceres G, Baeyens J. Thermal energy storage: "How previous findings determine current research priorities". Energy 2012; 39: 246-57.

http://dx.doi.org/10.1016/j.energy.2012.01.024

[5] BERR. Heat Call for Evidence (No. URN 08/519). Energy Group, Department for Business, Enterprise and Regulatory Reform (BERR), London, UK 2008.

[6] Carbon Trust. Carbon Trust Launches New Service to Help SMEs with Carbon Reduction 2010.

[7] Ammar Y, Joyce S, Norman R, Wang Y, Roskilly AP. Low grade thermal energy sources and uses from the process industry in the UK. Appl Energy 2012; 89: 3-20. http://dx.doi.org/10.1016/j.apenergy.2011.06.003

[8] Naish C, McCubbin I, Edberg O, Harfoot M. Outlook of energy storage technologies (Study No. IP/A/ITRE/FWC/ 2006-087/Lot 4/C1/SC2). European Parliament's committee on Industry, Research and Energy 2008.

[9] Gil A, Medrano M, Martorell I, Lazaro A, Dolado P, Zalba B, Cabeza LF. State of the art on high temperature thermal energy storage for power generation. Part 1--Concepts, materials and modellization. Renew Sust Energ Rev 2010; 14: $31-55$ http://dx.doi.org/10.1016/j.rser.2009.07.035

[10] Medrano M, Gil A, Martorell I, Potau X, Cabeza LF. State of the art on high-temperature thermal energy storage for power generation. Part 2--Case studies. Renew Sust Energ Rev 2010; 14: 56-72. http://dx.doi.org/10.1016/j.rser.2009.07.036

[11] Zalba B, Marin JM, Cabeza LF, Mehling H. Review on thermal energy storage with phase change: materials, heat transfer analysis and applications. Appl Therm Eng 2003; 23: 251-83.

http://dx.doi.org/10.1016/S1359-4311(02)00192-8 
[12] Acem Z, Lopez J, Palomo Del Barrio E. $\mathrm{KNO}_{3} / \mathrm{NaNO}_{3}-$ Graphite materials for thermal energy storage at high temperature: Part I. - Elaboration methods and thermal properties. Appl Therm Eng 2010; 30: 1580-85.

http://dx.doi.org/10.1016/j.applthermaleng.2010.03.013

[13] Pincemin S, Py X, Olives R, Christ M, Oettinger $O$. Elaboration of conductive thermal storage composites made of phase change materials and graphite for solar plant. J Sol Energy Eng Trans-ASME 2008b; 130: 011005.1-011005.5.

[14] Agyenim F, Hewitt N, Eames P, Smyth M. A review of materials, heat transfer and phase change problem formulation for latent heat thermal energy storage systems (LHTESS). Rene Sust Energ Rev 2010; 14: 615-28. http://dx.doi.org/10.1016/j.rser.2009.10.015

[15] Castellón C, Medrano M, Roca J, Nogués $M$, Castell A, Cabeza LF. Use of Microencapsulated Phase Change Materials in Building Applications, in: Buildings $X$ Proceedings. Presented at the Thermal Performance of the Exterior Envelopes of Whole Buildings $X$ International Conference, ONRL, Clearwater Beach, Florida 2007.

[16] Chen H, Cong TN, Yang W, Tan C, Li Y, Ding Y. Progress in electrical energy storage system: A critical review. Prog Nat Sci 2009; 19: 291-12.

http://dx.doi.org/10.1016/j.pnsc.2008.07.014

[17] Maruoka N, Akiyama T. Development of PCM for high temperature application in the steelmaking industry, in: Annex 17, Advanced Thermal Energy Storage Techniques Feasibility Studies and Demonstration Projects. Presented at the 3rd Experts' Meeting and Workshop of Annex 17, Tokyo 2002.

[18] Regin AF, Solanki SC, Saini JS. Heat transfer characteristics of thermal energy storage system using PCM capsules: A review. Renew Sust Energ Rev 2008; 12: 2438-58. http://dx.doi.org/10.1016/j.rser.2007.06.009

[19] Sharma A, Tyagi VV, Chen CR, Buddhi D. Review on thermal energy storage with phase change materials and applications. Renew Sust Energ Rev 2009; 13: 318-45. http://dx.doi.org/10.1016/j.rser.2007.10.005

[20] Sharma SD, Sagara K. Latent Heat Storage Materials and Systems: A Review. Int J Green Energy 2005; 2: 1-56. http://dx.doi.org/10.1081/GE-200051299

[21] Kenisarin MM. High-temperature phase change materials for thermal energy storage. Renew Sust Energ Rev 2010; 14: 955-70.

http://dx.doi.org/10.1016/j.rser.2009.11.011

[22] Perry's Chemical Engineers' Handbook, $8^{\text {th }}$. Edition, Mc.Graw-Hill, New York 2008

[23] Laing D, Bahl C, Bauer T, Lehmann D, Steinmann W-D. Thermal energy storage for direct steam generation. Sol Energy 2011; 85: 627-33.

http://dx.doi.org/10.1016/j.solener.2010.08.015
[24] Jegadheeswaran S, Pohekar SD. Performance enhancement in latent heat thermal storage system: A review. Renew Sust Energ Rev 2009; 13: 2225-44. http://dx.doi.org/10.1016/j.rser.2009.06.024

[25] Khodadadi JM, Hosseinizadeh SF. Nanoparticle-enhanced phase change materials (NEPCM) with great potential for improved thermal energy storage. Int Comm Heat Mass Tran 2007; 34: 534-43.

http://dx.doi.org/10.1016/j.icheatmasstransfer.2007.02.005

[26] Fukai J, Hamada Y, Morozumi Y, Miyatake O. Effect of carbon-fiber brushes on conductive heat transfer in phase change materials. Int J Heat Mass Tran 2002; 45: 4781-92. http://dx.doi.org/10.1016/S0017-9310(02)00179-5

[27] Elgafy A, Lafdi K. Effect of carbon nanofiber additives on thermal behavior of phase change materials. Carbon 2005; 43: 3067-74.

http://dx.doi.org/10.1016/j.carbon.2005.06.042

[28] Delgado M, Lázaro A, Mazo J, Marín JM, Zalba B. Experimental analysis of a microencapsulated PCM slurry as thermal storage system and as heat transfer fluid in laminar flow. Appl Therm Eng 2012; 36: 370-77.

http://dx.doi.org/10.1016/j.applthermaleng.2011.10.050

[29] Chen B, Wang X, Zeng R, Zhang Y, Wang X, Niu J, Li Y, Di $\mathrm{H}$. An experimental study of convective heat transfer with microencapsulated phase change material suspension: Laminar flow in a circular tube under constant heat flux. Exp Therm Fluid Sci 2008; 32: 1638-46. http://dx.doi.org/10.1016/j.expthermflusci.2008.05.008

[30] Pitié F, Zhao CY, Cáceres G. Thermo-mechanical analysis of ceramic encapsulated phase-change-material (PCM) particles. Environ Eng Sci 2011; 4: 2117-24. http://dx.doi.org/10.1039/c0ee00672

[31] Pitié $F$, Zhao $\mathrm{CY}$, Baeyens J, Degrève J, Zhang HL. Circulating fluidized bed heat recovery/storage and its potential to use coated phase-change-material (PCM) particles. Appl Energy 2013; 109: 503-13. http://dx.doi.org/10.1016/j.apenergy.2012.12.048

[32] Cabeza LF, Castell A, Barreneche C, De Gracia A Fernández Al. Materials used as PCM in thermal energy storage in buildings: A review. Renew Sust Energ Rev 2011; 15: 1675-95. http://dx.doi.org/10.1016/j.rser.2010.11.018

[33] Bridges NJ, Visser AE, Fox EB. Potential of NanoparticleEnhanced Ionic Liquids (NEILs) as Advanced Heat-Transfer Fluids. Energ Fuel 2011; 25: 4862-64. http://dx.doi.org/10.1021/ef2012084

[34] Wu ZG, Zhao CY. Experimental investigations of porous materials in high temperature thermal energy storage systems. Sol Energy 2001; 85: 1371-80. http://dx.doi.org/10.1016/j.solener.2011.03.021

[35] Luptowski B. Development of Molten-Salt Heat Transfer Fluid Technology for Parabolic Trough Solar Power Plants 2011. 